\title{
Maan fosforin intensiteetti- ja kapasiteettitestit fosforilla lannoitettujen ja lannoittamattomien nurmikasvien fosforin oton ja pitoisuuden ennustajina
}

\author{
Into Saarela \\ Maa-ja elintarviketalouden tutkimuskeskus,31600Jokioinen, into.saarela@mtt.fi
}

\begin{abstract}
Johdanto
Maan viljavuuden tutkimista varten on kehitetty lukuisia kemiallisia pikamenetelmiä eli testejä, jotka perustuvat maanäytteen uuttamiseen erilaisilla vesiliuoksilla. Maa-analyysejä tehdään hyvin vaihtelevissa oloissa, ja samoja uuttomenetelmiä sovelletaan kasvintuotannossa useille ravinteille ja vieläpä maatalouden ympäristönsuojeluunkin. Sama testi ei kuitenkaan ole edes maatalouden kannalta paras kaikilla maalajeilla eikä tilanteissa. Hellavaraisemmat liuokset kuten vesi ja neutraalit suolat uuttavat ahtaalla liuos/maasuhteella tuskin muuta kuin maanesteen ravinteet. Vahvasti happamat ja emäksiset sekä tehokkaasti fosforia pidättäviä metalli-ioneja kelatoivat liuokset irrottavat runsaasti myös vaikealiukoista ja tiukasti maahiukkasten pinnoille pidättynyttä fosforia (Kaila 1964), jota kasvit eivät juuri voi käyttää. Maanesteen ravinnepitoisuutta näytteenottohetkellä osoittavat menetelmät ovat ns. intensiteettitestejä ja labiilien eli potentiaalisesti käyttökelpoisten ravinteiden määrää osoittavat kapasiteettitestejä. Useimmat menetelmät ovat edellisten välimuotoja.

Parhaiten juurten toimintaa vastaavat ns. desorptiotekniikat, joilla maasta irtoavia ravinteita poistetaan uuton aikana kemiallisilla keräimillä eli denutrifioidaan uuttoliuosta (Barkoff 1959). Fosforia tutkittaessa uuttoliuosta defosforoidaan joko anioninvaihtohartsilla tai rautaoksidilla päällystetyllä suodatinpaperilla. Jälkimmäisellä on mitattu myös P:n diffundoitumista paikallaan olevasta maasta (Saarela 1992) ja kartoitettu sen sijaintia (Saarela ja Saarela 2000). Lyhyet desorptiotestit osoittavat intensiteettiä ja pitkät kapasiteettia. Tavanomaisella uuttosuhteella (1:60) tehtävä vesiuutto ja happamilla mailla myös suomalainen asetaattimenetelmä ovat selvästi intensiteettitestejä, mutta monessa maassa käytettävä Olsenin menetelmä on happamilla maillamme kapasiteettitesti. MTT:n tutkimuksissa alumiinin ja raudan oksihydroksideihin pidättynyt P-fraktio (Al,Fe-P) kasvoi kapasiteettiluonteensa mukaisesti Olsenin P:n kasvaessa, mutta Al,Fe-P:n suhde oksalaattiliukoiseen Al:iin ja Fe:aan eli maan P-kyllästysaste osoitti intensiteettiä, ja se kasvoi vesi- ja asetaattiuutoilla määritettyjen maan P-pitoisuuksien mukana (Saarela ym. 2003a).

Vuonna 1999 käynnistettiin MTT:ssä Jokioisissa yhteistyössä Viljavuuspalvelun ja Pro Agria Maaseutukeskusten kanssa tutkimus, jossa selvitettiin maan kalium- ja fosforireservien saatavuutta biologisesti astiakokeella sekä kasvien ravinteiden saannin ennustamista kemiallisilla maaanalyyseillä. Kaliumreservien vapautumista maan mineraaleista on selostettu aikaisemmin (Saarela 2001, Saarela ja Mäntylahti 2002, Saarela ym. 2003b). Tässä kirjoituksessa esitetään yhteenveto maan P-varojen tutkimuksista saaduista tuloksista.
\end{abstract}

\footnotetext{
Aineisto ja menetelmät

Tutkimusta varten kerättiin Suomen peltoja hyvin edustava 56 maaerän aineisto, ja jokaisella maalla kasvatettiin koeastioissa peräkkäisinä vuosina koiranheinää, timoteita ja puna-apilaa. Ennen kasvatusta maasta määritettiin tavallisen viljavuuden lisäksi orgaanisen aineen ja saveksen pitoisuus, ja maan fosforia tutkittiin viljavuustutkimuksessa käytettävän asetaattimenetelmän (aset-P) lisäksi vesiuuttomenetelmällä (vesi-P) ja diffuusiotestillä (dif-P, Saarela 1992) sekä vahvalla happouutolla (Egner 1960), jonka päätarkoitus oli kaliumin vapautumisen ennustaminen (Saarela ym. 2003b). Kokeessa oli kaliumittoman ja fosforittoman lannoituksen riittävyyden toteamiseksi myös täyslannoitus, joka teki mahdolliseksi tutkia maan ravinteiden sekä fosfori- ja kaliumlannoituksen yhdys- ja yhteisvaikutuksia. Täyslannoitettujen astioiden fosforilannoitus oli maalitraa kohti vuosittain 120,80 ja 80 , yhteensä $280 \mathrm{mg} / \mathrm{l}$, joka vastaa $300+200+200$, yhteensä 700 kiloa fosforia hehtaarille 0.25 metrin paksuiseen kerrokseen. Fosforilannoite lisättiin diammoniumfosfaattiliuoksena keväällä ennen kylvöä ja sekoitettiin perusteellisesti maahan. Kesän myöhemmille sadoille annettiin kaikkia muita ravinteita mutta ei lainkaan fosforia.
} 


\section{Tulokset ja tulosten tarkastelu}

Vahvalla happouutollakin voitiin tunnistaa laihat turpeet, joista fosforia vapautui kasveille hyvin vähän. Samoista turpeista saatiin vesiuutolla ja diffuusiotestillä suhteettoman suuria P-lukuja. Asetaattimenetelmä oli ilman P-lannoitusta tehdyissä vertailuissa tasaisin, sillä se toimi jokseenkin yhtä hyvin koko aineistossa kuin 48 kivennäismaallakin (Kuva 1).

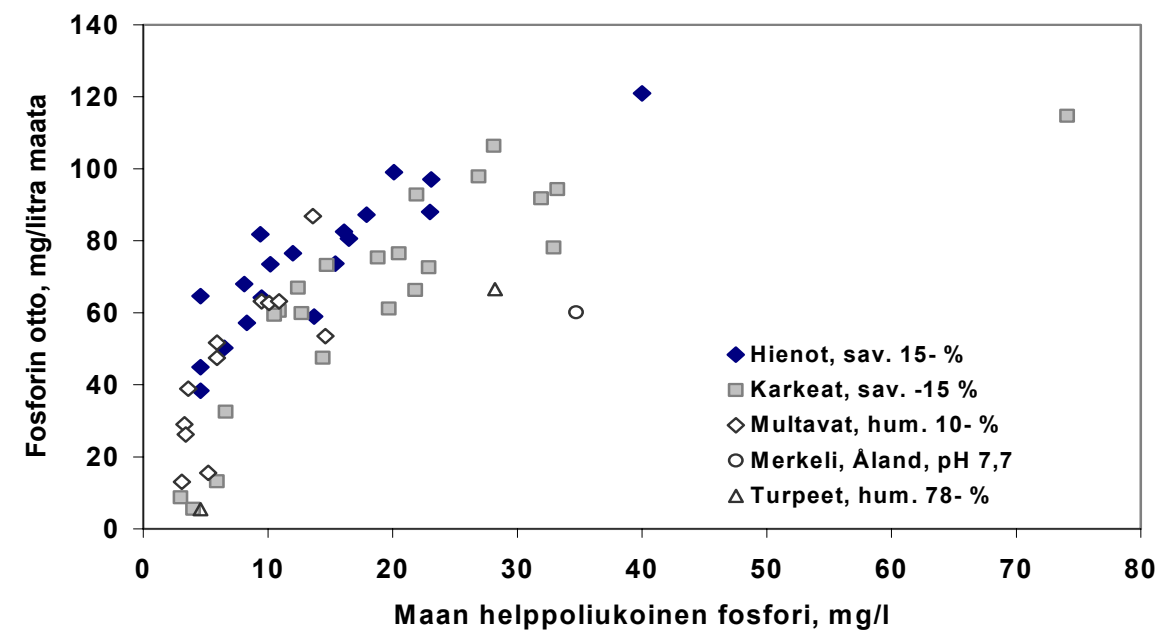

Kuva 1. Asetaattimenetelmällä määritetty maan helppoliukoinen fosfori ja ilman fosforilannoitusta kasvaneiden nurmikasvien fosforin otto kolmessa vuodessa. Log-lineaarisen mallin selvitysaste oli kaikkien kivennäismaiden (ilman ahvenanmaalaista merkeliä, pH korkeintaan 7.1) yhteisessä yhtälössä 73 \% sekä erikseen laskettuna yli 15 \% savesta sisältävillä mailla $82 \%$ ja karkeammilla mailla $88 \%$.

Kuten monissa aikaisemmissakin tutkimuksissa, vesiuuttomenetelmä näytti olevan kaikilla kivennäismailla hieman tarkempi (Kuva 2), mutta laskettaessa tulokset erikseen hienoille ja karkeille maille asetaattimenetelmä oli jopa hieman tarkempi, kun selvitysaste oli vesi-P:1lä 70-83\% ja asetP:1lä 82-88 \%. Ahvenanmaalainen kalkkipitoinen karkea hieta oli myös vesiuuttoisen fosforin mukaan parempi fosforin lähde kuin kasvien fosforin otto osoitti, mutta poikkeama oli pienempi kuin asetaattimenetelmällä. Molemmilla tutkituilla turvemailla asetaattimenelmä osoitti fosforin biologista saatavuutta paljon paremmin kuin vesiuuttomenetelmä. Diffuusiotesti oli fosforilla lannoittamattomilla mailla fosforin oton ennustajana hiukan huonompi, mutta fosforipitoisuuden ennustaja yhtä yhtä kuin asetaattimenetelmä.

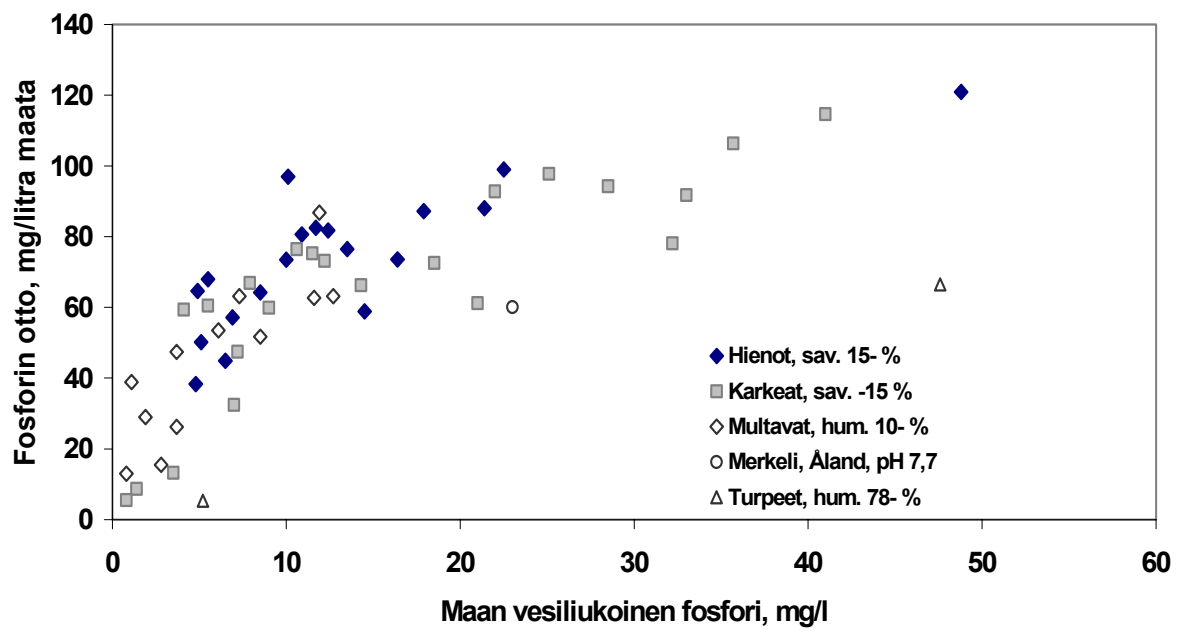

Kuva 2. Vesiuuttomenetelmällä määritetty maan fosfori ja ilman fosforilannoitusta kasvaneiden nurmikasvien fosforin otto kolmessa vuodessa. Log-lineaarisen mallin selvitysaste oli kaikkien kivennäismaiden (ilman ahvenanmaalaista merkeliä, $\mathrm{pH}$ korkeintaan 7.1) yhteisessä yhtälössä $77 \%$ sekä erikseen laskettuna yli $15 \%$ savesta sisältävillä mailla $70 \%$ ja karkeammilla mailla $83 \%$. 
Fosforilla lannoitetuilla kasveilla, joiden fosforin ottoa ja pitoisuutta verrattiin samoihin, ennen astiakokeen perustamista tehtyihin maa-analyyseihin kun edellä, vahva happouutto ennusti sekä fosforipitoisuutta että fosforin ottoa todella kehnosti. Asetaattimenetelmäkin osoitti fosforin ottoa lannoitetuista maista vain suuntaa-antavasti (selvitysaste 18-62 \%) ja fosforipitoisuutta välttävästi tai tyydyttävästi, selvitysaste $41-78 \%$ (Kuva 3).

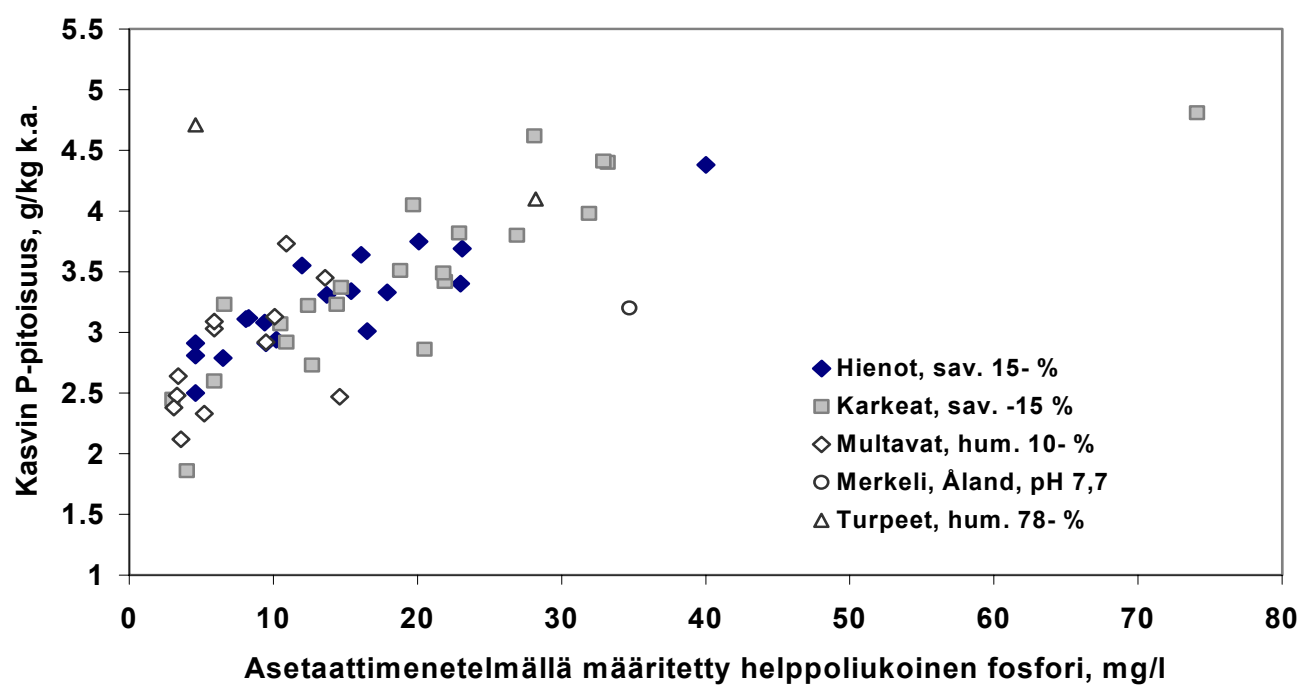

Kuva 3. Maan helppoliukoisen fosforin pitoisuus ennen lannoitusta ja fosforimäärällä $120 \mathrm{mg} / \mathrm{l} \mathrm{maata}$ lannoitetun koiranheinän fosforipitoisuus säilörehuasteella.

Huomattava tulos oli se, että vesiuutto- ja diffuusiomenetelmä ennustivat fosforilla lannoitettujen nurmikasvien fosforin ottoa ainakin välttävästi (selvitysaste 38-71 \%) ja fosforipitoisuutta jopa suhteellisen tarkasti, selvitysaste 36-84\% (Kuva 4). Vesiliukoisen fosforin suhteellisen pienet pitoisuudet karkeissa maissa (Kuva 5) merkitsevät sitä, että kivennäismaiden karkeuden huomioon ottaminen tulosten tulkinnassa on tärkeämpää asetaattimenetelmällä kuin vesiuuttomenetelmällä. Aikaisemmissa tutkimuksissa asetaattimenetelmä on ollut herkempi myös maan liiallisen happamuuden aiheuttamille virheille.

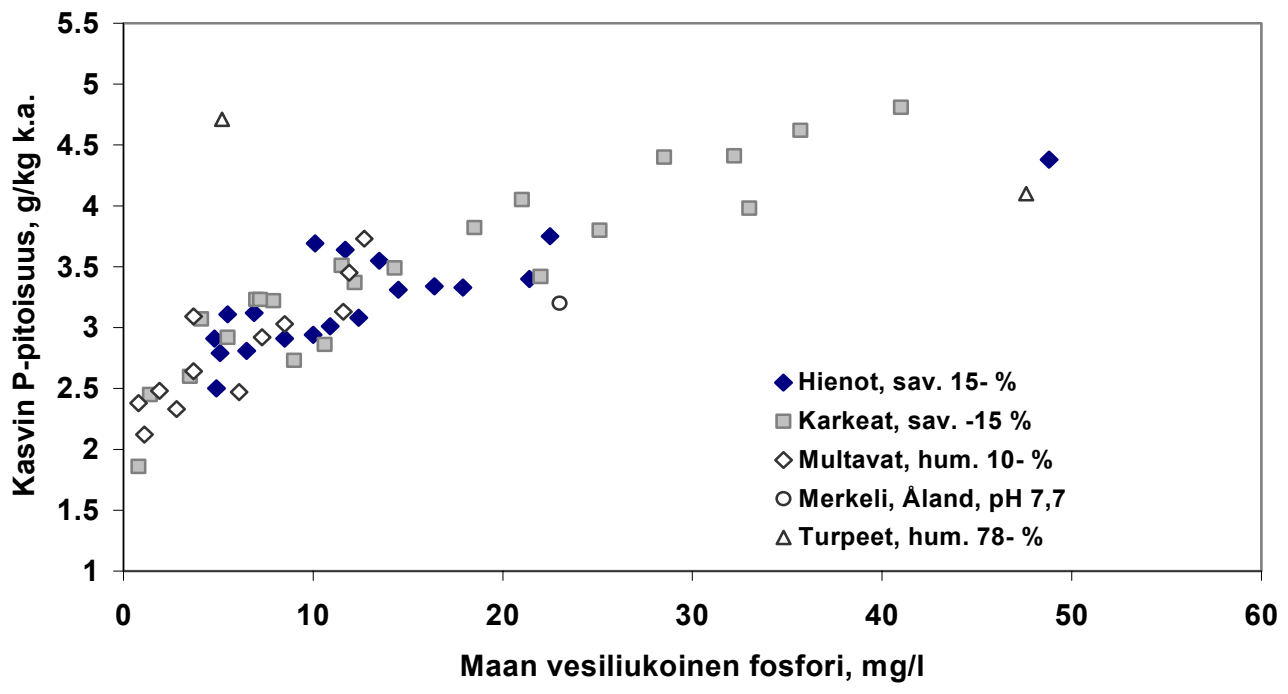

Kuva 4. Vesiuuttomenetelmällä määritetty maan fosfori ennen lannoitusta ja fosforimäärällä $120 \mathrm{mg} / \mathrm{l} \mathrm{maata}$ lannoitetun koiranheinän fosforipitoisuus säilörehuasteella. 


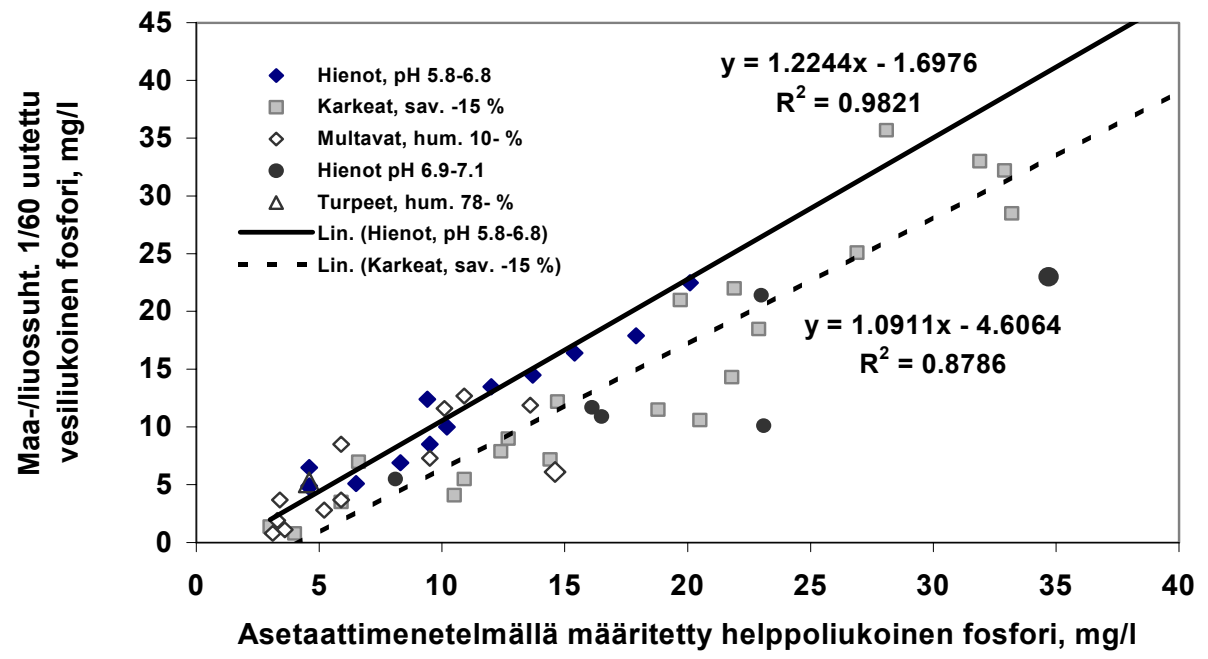

Kuva 5. Maan liukoinen fosfori asetaattimenetelmällä ja vesiuuttomenetelmällä määritettynä. Isoilla merkityissä maan $\mathrm{pH}$ on arveluttavan korkea, multamaassa 7.1 ja ahvenanmaalaisessa hienossa kalkkipitoisessa, savisessa karkeassa hiedassa eli merkelissä 7.7.

\section{Johtopäätökset}

Tutkimuksen mukaan happamien ja neutraalien maiden fosforitilan intensiteettitekijää mittaavat maaanalyysimenetelmät soveltuvat Suomen viljelymaille kasvien fosforin saannin ja lannoitustarpeen ennustamiseen. Maan fosforivarojen ja lannoituksen yhteisvaikutusta sekä lannoituksen optimaalista fosforimäärää näyttivät ainakin kivennäismailla osoittavan parhaiten vesiuuttomenetelmä ja diffuusiotesti, jotka mittaavat maan fosforitilan intensiteettitekijää tarkemmin kuin asetaattimenetelmä. Analyysitulosten tulkinta maalajin ja multavuuden perusteella, kuten maan viljavuutta tutkittaessa nykyisin tehdään, sekä liian happamien peltojen kalkitus parantavat kuitenkin asetaattimenetelmän luotettavuutta. Näytteenotosta alkaen oikein tehtynä ja tulkittuna tämä vanha ja useiden tutkijoiden vahvasti epäilemä "amerikkalaisen pikatestin" muunnos on edelleen varsin käyttökelpoinen maan Ptilan ja lannoitustarpeen tutkimusmenetelmä.

\section{Kirjallisuus}

Barkoff, E. 1959. Über die Fraktionierung der Bodenphosphate unter Verwendung eines automatishen Apparates mit Ionenaustauscher. Acta Agralia Fennica 94, 12. 36 p.

Egner, H., Riehm, H. \& Domingo, W. H. 1960. Untersuchungen über die chemische Bodenanalyse als Grunlage für die Beurteilung des Nährstoffstuztandes der Böden. Kungl. Lantbr.högsk Annaler 26: 199-215.

Kaila, A. 1964. Fractions of inorganic phosphorus in Finnish mineral soils. J. Sci. Agric. Soc. Finl. 36: 1-13.

Saarela, I. 1992. A simple diffusion test for soil phosphorus availability. Plant and Soil 147: 115-126.

Saarela, I. 2001. Maan kaliumvarojen käyttökelpoisuus nurmikasveille. Suomen Nurmiyhd. Julk. 14: 100-107.

Saarela, I. \& Mäntylahti, V. 2002. Kiillepitoisten karkeiden maiden kaliumin vapautuminen kasveille. Pro Terra 15: $140-142$.

Saarela, I. \& Saarela, K. 2000. Mapping spatial variation of diffusible soil P by in situ colouring in Fe-oxide paper. Comm. Soil Sci. Plant Anal. 31: 2019-2025.

Saarela, I., Järvi, A., Hakkola, H. \& Rinne, K. 2003a. Phosphorus status of diverse soils in Finland as influenced by long-term P fertilisation. I. Native and previously applied P at 24 experimental sites. Agric. Food Sci. Finl. 12: 117-132.

Saarela, I., Saarela, K. \& Mäntylahti, V. 2003b. Accurate prediction of potassium release by simple extraction: $2 \mathrm{M} \mathrm{HCl} 2 \mathrm{~h} 20^{\circ} \mathrm{C}$. NJF's $22^{\text {nd }}$ Congress, Turku 1.4.-7. 2003. Proc. p. 351. 
SUOMEN MAATALOUSTIETEELLISEN SEURAN TIEDOTE NRO 19 